\title{
Consumer Ecoregions: Geographic Segmentation of the Eastern Conterminous United States of America
}

\author{
Justin O. Holman \\ Colorado State University, Pueblo \\ Allie Hacherl \\ Western Kentucky University
}

\begin{abstract}
A new partition of geographic regions in the Eastern US, based on environmental variables rather than political borders, is introduced as an alternative approach to aggregation of consumer demand data. The classification exercise described in this paper led to the definition of twelve distinct geographic regions representing the same area as seventeen corresponding Western States in Holman (2020). The same exercise is repeated here to define twelve distinct regions representing the same area as thirty-one corresponding Eastern States and the District of Columbia. The purpose of this classification exercise in both cases is to create Consumer Ecoregions (CERs) that, in comparison to the partition of states, demonstrate significantly less variability in terms of population, economic output, and land area while better representing unique climates and landscapes. This serves the broader goal of developing a partition for the entire conterminous United States which can be used to analyze business and economic data through a geographic lens that provides a more concise view of distinct regions.
\end{abstract}

Keywords: consumer, geographic segmentation, regional aggregation

\section{INTRODUCTION}

In 2020, I published "Consumer Ecoregions: Geographic Segmentation of the Western Coterminous United States of America," which introduced a partition of Consumer Ecoregions (CERs) designed to facilitate a data aggregation alternative to seventeen western States. In business analytics, a foundational element of practice is the quantification and geographic aggregation of consumer demand. Often, geographic data aggregation is based on US Postal Service ZIP Codes, political state and county boundaries, or US Census Bureau partitions. Though Census Tracts, Block Groups, or Core-Based Statistical Areas (CBSA) provide an acceptable spatial framework for local-level analyses, partitions using Census Divisions, Regions, or State borders are often unable to sufficiently explain patterns of variation in business data at the regional level. This is especially true in cases involving impactful environmental factors. In this paper, I will use similar objectives and stratagem to partition the Eastern thirty-one states to more effectively facilitate analysis of regional patterns in consumer demand when political borders are inappropriate.

The most common map of the United States is its political partitioning into State borders, which also serves as the typical geographic segmentation used for data aggregation. As young as kindergarten, students are introduced to the fifty States and Washington, D.C. As adults, we are rarely inclined to question whether 
the application of our political partition system to apolitical data is appropriate and useful. In reality, these political borders are often less than ideal for data aggregation or analysis of geographic patterns of variation in demographic, economic, or business data. This is especially true when a lurking environmental variable exists and influences the circumstances.

This paper demonstrates a partition of Consumer Ecoregions (CERs) created to facilitate a data aggregation alternative to State boundaries. Because this is a continuation of a 2020 article that examines the western half of the conterminous United States, the CERs introduced are intended to function as an alternative to thirty-one Eastern States and the District of Columbia.

\section{LITERATURE REVIEW}

According to geographer Hart (1982), when partitioning regional frameworks, one must consider change over time, the environmental factors, and the behavior of humans in that area. In keeping with this conceptualization of regions, many different fields of study have worked to create and study geographic partitions to help understand patterns of human action and often, apply that understanding to a specific purpose.

In the existing literature, there are a number of studies that analyze patterns of cultural identity and create alternative geographic partitions in North America to illustrate them. An example of this type of study is the Patchwork Nation project (Jefferson Institute, 2008), which created a framework to analyze cultural and geographic data during the 2008 presidential election. Some popular non-fiction books (Garreau, 1981; Chinni and Gimpel, 2010; Woodard, 2012) and other academic journal articles (Hawkins et al., 1980) have emerged from this and similar projects. These works create conceptual frameworks to establish both conterminous and non-conterminous locations where shared history, culture, and political orientation have formed distinct regional identities. Some effort has been made to apply these principles and frameworks to explaining entrepreneurial and economic data (Audretsch et al., 2017). Though these inquiries involve some loosely defined geographic segmentation through the use of maps, they are focused more on explaining the geographic distribution of culture and do not include a framework for facilitating quantitative geographic data analysis.

There have also been studies applying geographic segmentation to research in marketing and consumer data. Many of these publications examine the interplay between psychographic and geographic segmentation (Lesser \& Hughes, 1986; Kahle et al., 1992; Umesh, 1987; Mitchell, 1983). Some of the systems to emerge from these publications, such as the Values \& Lifestyles psychographic framework (Michell, 1983) or the List of Values system (Kahle et al., 1992) have been compared in their capacity to provide information about consumer demographic data for effective segmentation (Novak \& MacEvoy, 1990). More recently, some studies have endeavored to validate market segments (Tonks, 2009) but none of these attempts to concretely define geographic segments or use data analysis to create a framework for alternative geographic partitions. So far, those that do attempt geographic segmentation using data analysis are focusing on a particularly narrow question, such as the distribution of labor markets in urban areas (Dash Nelson et al., 2016) as opposed to a focus on creating CERs for broader business applications.

Beginning in the latter half of the 20th century, the term "bioregionalism" emerged in a separate research thread. It is used to describe a movement advocating political boundaries that are more aligned with ecological boundaries (McGinnis, 1999). Since then, the principles of bioregionalism have been used to advise changes to the future course of human action (Fanfani and Ruiz, 2020) and its consequences for the economy have been explained in more concrete terms (Scott Cato, 2013). While the bioregionalism movement does at times involve geographic segmentation, its intentions in doing so are to facilitate a regional governance structure more closely guided by natural resources, whereas my purpose in developing CERs is to offer a more effective technique to aggregate demographic and economic data for business applications.

Finally, several frameworks of ecoregions have been designed by interdisciplinary collaboration between geography and ecology. Led by Bailey (1998), the US Forest Service published a set of Ecoregions that are divided into four levels. Each level in the hierarchy is more specifically defined by different 
environmental factors, making them useful for supporting the forest resource management work of the US Forest Service but also applicable to a wide variety of environmental research. A similar project was created by the US Environmental Protection Agency (EPA), led by Omernik (1987), which developed a set of Ecoregions that serve as a spatial framework for environmental resource management (Omernik and Griffith, 2014; McMahon et al., 2001; Loveland \& Merchant, 2004). The EPA Ecoregions have since appeared in multiple studies (Fusco et al., 2019; Liu and Peng, 2019) as a supporting structure for effective ecological data analysis. EPA Ecoregions play a key role in my research as they provide an effective conceptual framework for shaping the partition of CERS. They cover coterminous regions but are not bound by political state borders, as are the partitions of CERS I have designed. Additionally, there are three levels of EPA Ecoregions, intending to range from broad alignment of ecological characteristics to detailed categorization of local environmental factors that support local bodies in more specific management of their resources. Though CERS are for business applications, I similarly intend for this partitioning to support local businesses in applying data to their specific consumer base.

\section{DATA AND METHODS}

The region classification exercise was guided by three objectives. My first objective was to define fewer regions than States while covering the same geographic area, using counties as the base unit of geography. It is difficult to focus on anything beyond the very top and the very bottom of any ranked list when it considers 50 separate entities, as we often do when reviewing State-level statistics. For this reason, I decided to define no more than 30 CERs for the entire conterminous United States and, for this exercise, fewer than 15 CERs for the Eastern U.S. Secondly, I wanted each region to be as distinct as possible in its climate, landscape, economics, and consumer culture from its neighboring regions. In some cases, such as the Appalachian Mountains comprising their own individual region, this is a relatively straightforward process. However, in other cases, a State border may be the best available dividing line, such as the distinct transition from the Northern Lakes region to the Central Plains region at the border between Minnesota and Iowa. Finally, to the extent possible, I wanted regions with the partition to be similar in terms of size, population, and economic activity. When examining data through the lens of the 50 U.S. States, the disparities in these categories can be significant enough to make comparison invalid if not impossible, as evidenced by differences in land area between States like Texas $(\sim 269 \mathrm{k} \mathrm{sq} \mathrm{mi})$ and Rhode Island $(\sim 1.2 \mathrm{k} \mathrm{sq} \mathrm{mi})$ or the population differences between California ( $\sim 40$ million) and Wyoming $(\sim 0.6$ million) or the economic differences between New York ( $\sim 1.75$ trillion) and Vermont ( $\sim \$ 0.035$ trillion).

To arrive at this formal iteration of Eastern U.S. CERs, a variety of environmental, demographic, and economic variables were analyzed and synthesized. In keeping with my methods for partitioning Western ecoregions (Holman, 2020), I utilized temperature and precipitation data from the National Oceanic and Atmospheric Administration's Climate Normals for 1981-2010 (Arguez et al., 2012), the topographical patterns of large-scale landscape features (USGS, 2020), the spatial extent of freshwater river networks (USGS 2019), direct incoming Solar Radiation (Sengupta et al., 2018) from the National Renewable Energy Lab and Ecoregions (Omernik, 1987) used by the EPA for environmental research management. With these data sources, I determined significant environmental differences and identified possible boundaries between regions. In addition, I examined population estimates from the US Census Bureau's American Community Survey (2018) and local area gross domestic product (GDP) provided by the US Bureau of Economic Analysis (2019) in order to articulate significant demographic and economic differences. Variables were analyzed at the county level and were viewed in map format whenever available in order to base regional classifications on visual assessment of natural borders and ecotones (Kark, 2013). If a salient natural border wasn't obvious, state boundaries were also considered.

While this classification exercise was driven by data, decisions on where exactly to locate borders between individual counties to form regions were ultimately subjective in nature. Describing and defending each individual border placement decision is beyond the scope of this paper. 


\section{CONSUMER ECOREGIONS}

The result of this classification exercise was the definition of twelve separate CERs intended to be an alternative to the thirty-one Eastern States plus the District of Columbia occupying the same geographic area. The twelve CERs are illustrated in Figure 1 and each region is described in the following paragraphs.

\section{FIGURE 1 \\ MAP OF THE EASTERN US \& CORRESPONDING CONSUMER ECOREGIONS}

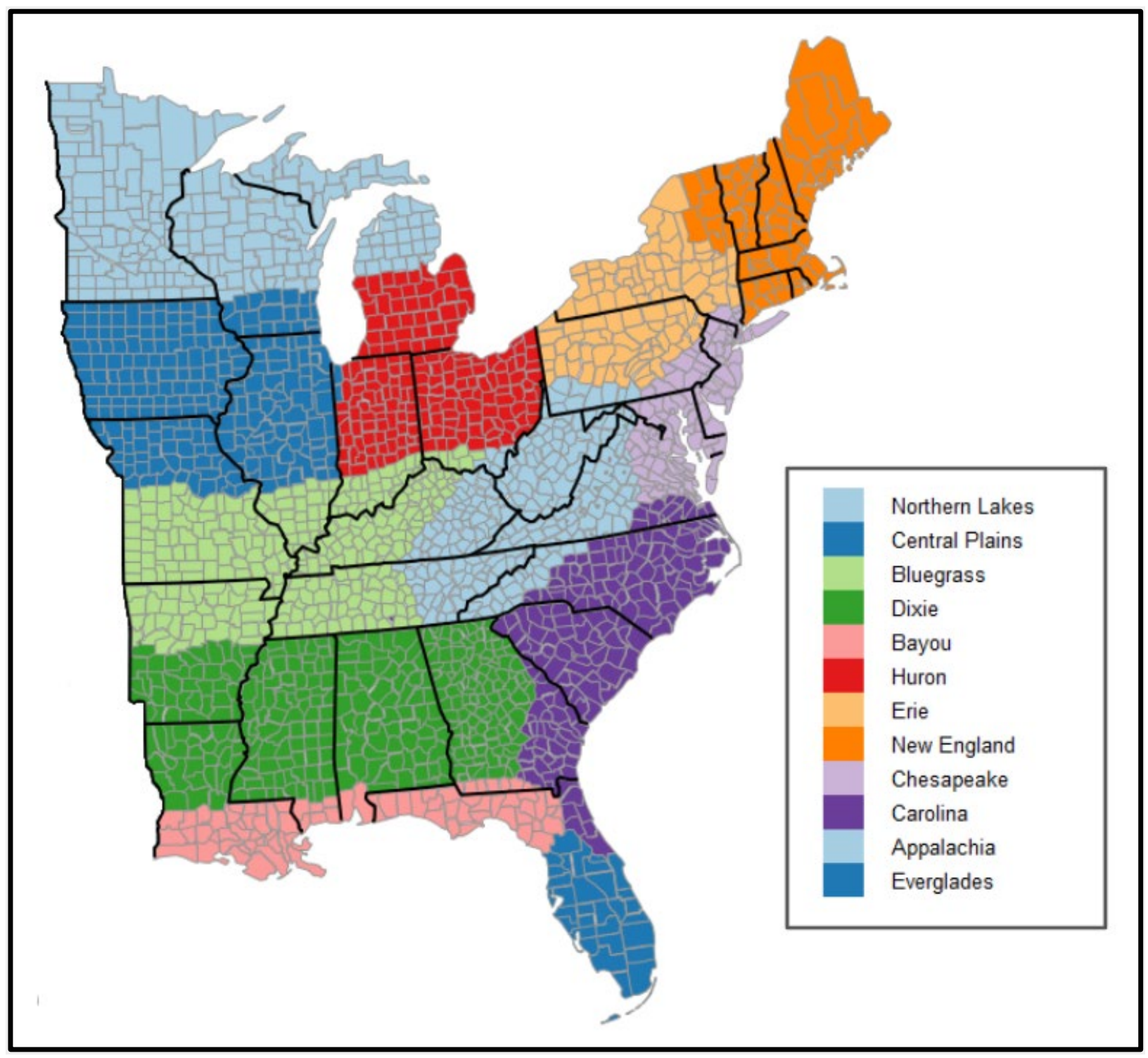

The Northern Lakes region contains the entirety of Minnesota, northern Wisconsin, and the Upper Peninsula and northern mainland Michigan. This region borders Lake Superior and Lake Michigan to the east. It experiences warm summers and frigid winters with frequent storms. While much of the western portion of the Northern Lakes is rolling hills and fertile soil suitable for farming, the terrain becomes more heavily forested closer to the Great Lakes. Major population centers include Minneapolis, St. Paul, Madison, and Marquette. 
The Central Plains incorporates all of Iowa, southern Wisconsin, and parts of Illinois and Missouri. The former natural prairie and vegetation of these areas have largely been replaced by agriculture, which is a driving economic force in the region. However, this region has a largely nonagricultural workforce, dominated by service industries and manufacturing. Major cities include Chicago, St. Louis, Milwaukee, and Des Moines.

The Dixie region begins in southern Arkansas and reaches eastward across northern Louisiana, the entirety of Mississippi and Alabama, and western Georgia. It has a particularly warm climate compared to the rest of the United States that allows for a longer growing season, making agriculture a critical enterprise to the area's economy. Manufacturing has also grown exponentially to become the largest driver of the Dixie economy in the past century. The Dixie region has a diverse population, as its agricultural apparatus for stable crop production was built on the plantation system and Black agricultural labor. Accordingly, the region's socioeconomic history continues to influence its political and social issues in the present. Its socioeconomic history and cultural identity have also been expressed and shared widely through literature and music stemming from the region. Major metropolitan hubs include Jackson, Montgomery, Birmingham, and Atlanta.

The Bayou includes the coastal areas of southern Louisiana, Mississippi, Alabama, and the Florida panhandle. Its topography is split between coastal beaches and marshy wetlands. Vegetation and animal population vary widely from region to region but include moss, deciduous trees, shrimp, and alligators. Its climate is humid subtropical, and it is susceptible to hurricanes and flooding. Economic development revolves around fishing and shrimping, cargo shipping at major ports, and drilling offshore oil and gas deposits. The largest population centers are New Orleans, Tallahassee, and Pensacola.

The Huron region is, essentially, southern Michigan, northern Indiana, and western Ohio. It experiences hot summers and cold winters, with relatively uniform precipitation throughout the year and a high likelihood for tornadoes and severe storms in the springtime. The Huron is considered a hub for manufacturing, science, and industry, though it also encompasses some farmland. Detroit, Columbus, and Indianapolis are major metropolitan centers.

The Bluegrass region spans southern Missouri and northern Arkansas to western Kentucky and Tennessee. It is situated on the Ozark Plateau to the west, which is characterized by high rocky bluffs, heavily forested highlands, and many underground waterways. Its ecosystem includes many rare and endangered species. To the east, the terrain is largely fertile cropland, with some scattered forested hills. Major agricultural products in this area are grain, corn, soybeans, and wheat. In addition to agriculture, mining, and timber, tourism is a primary industry. Summers are hot and humid, and winters are cold but not severe. Though the overall population density of the area is low, major population centers include St. Louis, Cincinnati, Louisville, Nashville, Memphis, and Fayetteville.

The Appalachia region covers eastern Kentucky and Tennessee, West Virginia, southwest Pennsylvania, and western North Carolina and Virginia. The main feature of this region's terrain and its namesake is the Appalachian Mountains, which stretch for approximately 1,500 miles and are surrounded by plateaus and hills. The flora is largely deciduous hardwood trees but varies widely depending on geology, latitude, and elevation in the different areas of the mountains. In the nineteenth and twentieth centuries, the mountains' flora and natural deposits of coal made it a popular site for the logging and mining industries. However, the area has long experienced high levels of poverty, reflected by a poverty rate of $19.7 \%$ compared to the national average of 15.6\% (Appalachian Regional Commission, 2014). The geography of the mountains keeps population centers scattered at remote distances from one another, but major cities include Knoxville, Chattanooga, Asheville, and Charleston.

The New England region is comprised of Maine, Vermont, New Hampshire, Massachusetts, Connecticut, Rhode Island, and some of upstate New York. The climate of this region varies widely, with southern New England receiving far less snow and much warmer temperatures than the northern area. There is some risk of hurricanes landing on the coast. Its terrain includes rivers and lakes, deciduous forests, farmland, mountain ranges, rocky coasts, and beaches. Central New England becomes popular with tourists in the fall when the leaves change in the dense forests. Likewise, the mountainous regions that attract heavy snowfall are in-demand tourist destinations in the winter for skiing. Historically, other economic advantages 
in New England have included industrialization and natural resources due to its long coastline. Today, it is also a center for technology development and education, with larger population centers in state capitals Albany and Providence.

The Erie region includes western New York, eastern Ohio, and northwest Pennsylvania. Because the Erie region borders Lake Erie and Lake Ontario, it has relatively cool summers and extremely cold winters with high amounts of snowfall. Wetlands surround the lakes with distinct flora, many species of which grow directly on or submerged in the water. Expanding outwards from there, the area is largely plains where farming is popular, then the Erie region becomes more mountainous. It also includes the upper region of the Allegheny National Forest, with its own distinct flora and fauna. Major metropolitan centers are Buffalo and Cleveland.

The Chesapeake region covers the eastern Pennsylvania, New York City metropolitan area, New Jersey, Delaware, Maryland, the Washington, D.C. metropolitan area, and coastal Virginia. It includes both the capital of the United States and the country's most populous city, making it the most populous region of the Eastern ecoregions. Accordingly, the economy relies heavily on finance, technology, and government employment. Additionally, chemical manufacturing and tourism support the economy. Though the area is densely populated, there are still some rolling hills in northern Virginia and the Piedmont Plateau of Maryland. Generally, the area has hot and humid summers with cold and rainy winters, largely influenced by the adjacent coast. Other major metropolitan areas include Philadelphia and Baltimore.

The Carolina region incorporates southern Virginia, North Carolina, South Carolina, eastern Georgia, and northern Florida. The climate varies, becoming increasingly warmer overall further south with shorter, milder winters in South Carolina, Georgia, and Florida. Consistently across the region, the terrain ranges from the foothills of the Appalachian Mountains in the west, plateau and flatlands in the center, and coastline to the east. Similar to the Dixie region, agriculture is a major staple of the economy, particularly in the middle and western sections of each state. The coastline economy hinges on tourism as well as shipping and trading. Major population hubs include Charlotte, Charleston, Savannah, and Jacksonville.

Finally, the Everglades region covers all of southern Florida, which is bordered on the west by the Gulf of Mexico and on the east by the Atlantic Ocean. While other wetlands typically originate from rivers and streams, the Everglades is a vast watershed covering nearly the entirety of southern Florida. Freshwater from the northern Lake Okeechobee meets saltwater from the sea to the south, creating an ecosystem that is the only one of its kind on the planet. Therefore, it includes a large variety of plants and animals indigenous and unique to the region, in addition to more common varieties including cypress trees and mangrove forests. The economy relies heavily on the natural resources in the area, particularly marine life. Orlando, Tampa, and Miami are major population centers as well as tourist destinations.

\section{RESULTS AND DISCUSSION}

The resulting partition of CERs meets the objectives described above. The number of CERs is twenty fewer units than the corresponding thirty-one States and the District of Columbia. The regions represent distinct climate zones within the Eastern US. There is an inherent tradeoff between minimizing the number of regions and identifying meaningful boundaries between distinct climates, but I think this partition represents a useful compromise. Finally, these regions are more consistent in terms of population, economy and land area as summarized for each CER in Figure 2. 
FIGURE 2

POPULATION, GDP AND AREA BY CONSUMER ECOREGION

\begin{tabular}{|l|r|r|r|r||}
\hline \hline Consumer Ecoregion & Counties & Population (2019) & GDP (thousands, \$) & \multicolumn{1}{c|}{ Area (Sq Mi) } \\
\hline Appalachia & 241 & $11,547,242$ & $499,766,765$ & 97495.4 \\
\hline Bayou & 79 & $6,953,496$ & $316,073,905$ & 54544.4 \\
\hline Bluegrass & 293 & $15,256,804$ & $702,684,032$ & 144978.1 \\
\hline Carolina & 187 & $19,102,413$ & $874,953,349$ & 101417.7 \\
\hline Central Plains & 242 & $22,422,505$ & $1,286,029,572$ & 140375.1 \\
\hline Chesapeake & 123 & $41,692,558$ & $3,071,833,670$ & 39250.3 \\
\hline Dixie & 322 & $18,075,492$ & $825,399,442$ & 179576.6 \\
\hline Erie & 90 & $10,502,006$ & $491,653,758$ & 65631.7 \\
\hline Everglade & 31 & $16,400,151$ & $752,134,747$ & 31157.7 \\
\hline Huron & 182 & $24,597,271$ & $1,219,102,584$ & 88098.9 \\
\hline New England & 74 & $15,394,375$ & $984,319,454$ & 76645.3 \\
\hline Northern Lakes & 182 & $9,186,572$ & $488,462,020$ & 159923.1 \\
\hline Totals & 2046 & $211,130,885$ & $11,512,413,298$ & 1179094.1 \\
\hline Sources: US Census Bureau (Population, Area), US Bureau of Economic Analysis (GDP) \\
\hline
\end{tabular}

In comparison to the thirty-one States, the CERs are less variable in terms of population, economic output and land area as illustrated in Figure 3. Note the cluster of small States in contrast to the large CERs including Chesapeake, an outlier in terms of large population and GDP. Under the "Area" column the CERs are larger on average, as necessary to reduce the number of regions, and have a wider range of sizes.

FIGURE 3

DISTRIBUTION OF POPULATION, GDP AND LAND AREA

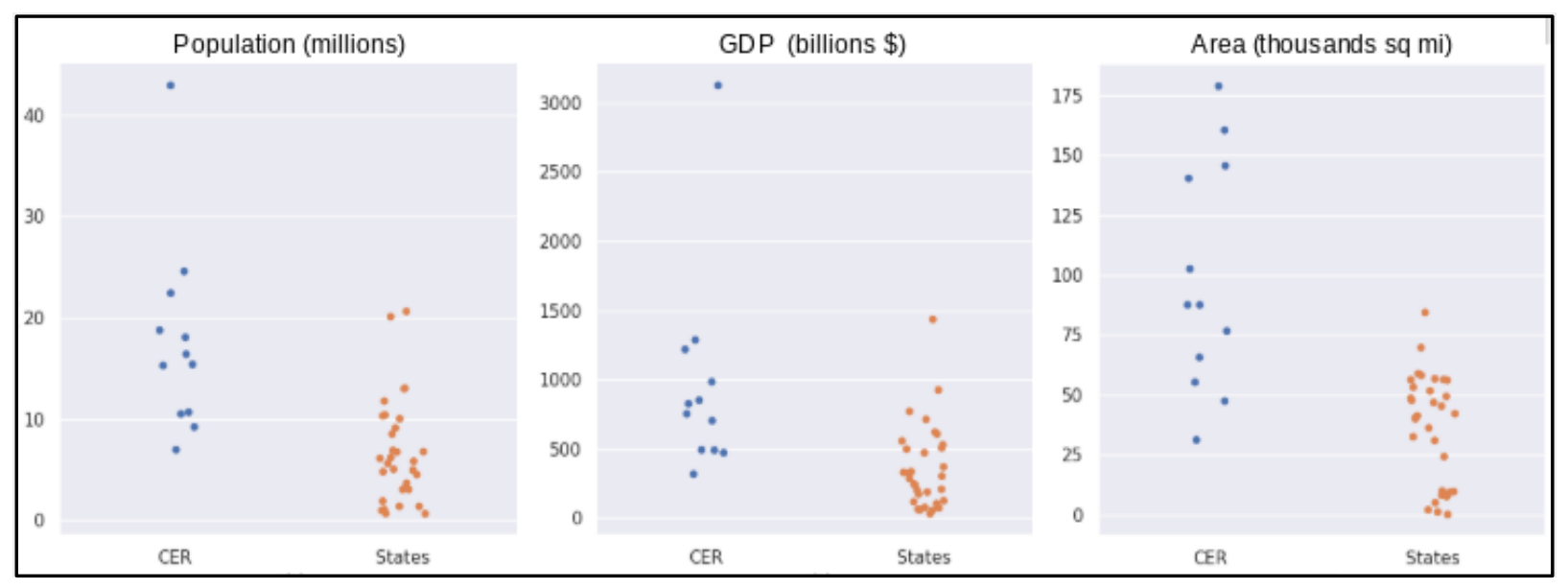

Another way to explore differences in variability is to calculate the coefficient of variation (Mendershausen, 1937) and compare the resulting coefficients from each group. As you can see in Figure 4, the coefficient of variation is significantly lower for CERs in Population, GDP and Area than for the corresponding thirty-one States and Washington DC. 
FIGURE 4

COEFFICIENT OF VARIATION FOR STATES AND CONSUMER ECOREGIONS

\begin{tabular}{||l|l|r|r|r|}
\hline \hline & & \multicolumn{1}{|c|}{ Population } & \multicolumn{1}{c|}{ GDP } & \multicolumn{1}{|c|}{ Area } \\
\hline States & Mean & $6,597,840$ & $359,762,916$ & 36,847 \\
\hline & Standard Deviation & $5,103,374$ & $305,741,453$ & 22,664 \\
\hline & Coefficient of Variation & $\mathbf{0 . 7 7 3}$ & $\mathbf{0 . 8 5 0}$ & $\mathbf{0 . 6 1 5}$ \\
\hline CERs & Mean & $17,594,240$ & $959,367,775$ & 98,258 \\
\hline & Standard Deviation & $9,234,810$ & $728,434,121$ & 48,535 \\
\hline & Coefficient of Variation & $\mathbf{0 . 5 2 5}$ & $\mathbf{0 . 7 5 9}$ & $\mathbf{0 . 4 9 4}$ \\
\hline
\end{tabular}

There are several borders where State boundaries were utilized to separate two regions when no obvious natural border was more prominent or sufficiently concentrated in one area. This is the case in the border between Bluegrass and Dixie where the State border and 35th Parallel serve just as well as any other dividing line might. In contrast, there are instances where natural borders are clearly more appropriate for segmentation of consumers. For example, State boundaries in the Eastern US essentially ignore the Appalachian Mountains.

\section{CONCLUSION}

This paper serves my broader goal of developing a partition for the entire conterminous U.S. by determining ecoregions for the Eastern thirty-one states using the same methodology as my previous partitioning of the Western seventeen states (Holman, 2020). Eventually, my goal is to develop a partition for the conterminous North American continent according to this methodology. This paper represents another step towards achieving that objective, and I plan to build on it by making available the regioncounty assignment data for general use. I also intend to publish economic data aggregated by the CERs I have designed to highlight differences in patterns and analysis when using CERs versus States. Additionally, I plan to conduct empirical studies using various data sources to assess the relevance and effectiveness of these border demarcations and region configurations. My hope is that CERs will provide insights that can improve location-based decision-making for businesses and improve understanding of American geography for the public.

More generally, the aim of this research is to bring attention to the relative poverty of options for increasing or decreasing spatial resolution in business and economic data analysis. We are accustomed to capturing stock market valuations and the market price of other securities or commodities aggregating by month, week, day, hour, even the second, which exemplifies data analysis at high resolution in the temporal dimension. However, we typically do not spend much time considering how data analysis might be shaped by different geographic aggregations. This paper and future research on the subject will hopefully contribute to greater awareness of the relevance of the spatial dimension to business analytics. 


\section{REFERENCES}

Andreasen, A.R. (1966). Geographic mobility and market segmentation. Journal of Marketing Research, 3(4), 341-348.

Arguez, A., Durre, I., Applequist, S., Vose, R.S., Squires, M.F., Yin, X., . . Owen, T.W. (2012). NOAA's 1981-2010 U.S. Climate Normals: An Overview. Bulletin of the American Meteorological Society, 93, 1687-1697.

Audretsch, D.B., Obschonka, M., Gosling, S.D., \& Potter, J. (2017). A new perspective on entrepreneurial regions: Linking cultural identity with latent and manifest entrepreneurship. Small Business Economics, 48, 681-697.

Bailey, R.G. (1998). Ecoregions of North America. U.S. Department of Agriculture, Forest Service.

Bower, K. (2010). Looking Back and Ahead: A History of Cartography at the Census Bureau and What the Future Holds [Special joint symposium of ISPRS Technical Commission IV \& AutoCarto]. ASPRS/CaGIS 2010 Fall Specialty Conference, Orlando, Florida.

Chinni, D., \& Gimpel, J. (2010). Our patchwork nation: The surprising truth About the "real" America. Gotham Books.

Dash Nelson, G., Rae, A., \& Rosenbloom, J.L. (2016). An economic geography of the United States: From commutes to megaregions. PLOS One, 11(11), p.e0166083-e 0166083.

Davenport, T.H. (2006). Competing on Analytics. Harvard Business Review.

Fanfani, D., \& Ruiz, A.M. (Eds.). (2020). Bioregional planning and design volume 1: Perspectives on a transitional century. Springer Nature Switzerland AG.

Fonstad, M., Pugatch, W., \& Vogt, B. (2003). Kansas is Flatter than a Pancake. Annals of Improbable Research, 9.3. Retrieved from https://www.improbable.com/airchives/paperair/volume9/v9i3/kansas.php

Fusco, E.J., Finn, J.T., Balch, J.K., Nagy, R.C., \& Bradley, B.A. (2019). Invasive grasses increase fire occurrence and frequency across US ecoregions. Proceedings of the National Academy of Sciences, 116(47), 23594-23599.

Garreau, J. (1981). The Nine Nations of North America. Houghton Mifflin.

Hart, J.F. (1982). The highest form of the geographer's art. Annals of the Association of American Geographers, 72(1), 1-29.

Hawkins, D.I., Roupe, D., \& Coney, K.A. (1980). The influence of geographic subcultures in the United States. Advances in Consumer Research, 8, 713-717.

Holman, J.O. (2020). Consumer Ecoregions: Geographic Segmentation of the Western Conterminous United States of America. Journal of Applied Business and Economics, 22(11).

Kahle, L.R., Liu, R., \& Watkins, H. (1992). Psychographic variation across United States geographic regions. Advances in Consumer Research, 19, 346-352.

Kark, S. (2013). Effects of Ecotones on biodiversity. In S.A. Levin (Ed.), Encyclopedia of Biodiversity (2nd ed., pp. 142-148).

Lesser, J.A., \& Hughes, M.A. (1986). The generalizability of psychographic market segments across geographic locations. Journal of Marketing, 50, 18-27.

Liu, J.C., \& Peng, R.D. (2019). The impact of wildfire smoke on compositions of fine particulate matter by ecoregion in the Western US. Journal of Exposure Science \& Environmental Epidemiology, 29(6), 765-776.

Loveland, T.R., \& Merchant, J.M. (2004). Ecoregions and ecoregionalization: Geographical and ecological perspectives. Environmental Management, 34(S1), 1-13.

McGinnis, M.V. (1999). Bioregionalism. Routledge.

McMahon, G., Gregonis, S.M., Waltman, S.W., Omernik, J.M., Thorson, T.D., Freeouf, J.A., . . Keys, J.E. (2001). Developing a spatial framework of common ecological regions for the conterminous United States. Environmental Management, 28(3), 293-316.

Mendershausen, H. (1937). Annual Survey of Statistical Technique: Methods of Computing and Eliminating Changing Seasonal Fluctuations. Econometrica, 5(3), 234-262. 
Mitchell, A. (1983). The nine American lifestyles: Who we are and where we're going. Macmillan Publishing.

Novak, T.P., \& MacEvoy, B. (1990). On comparing alternative segmentation schemes: The List of Values (LOV) and Values and Life Styles (VALS). The Journal of Consumer Research, 17(1), 105-109.

Omernik, J.M. (1987). Ecoregions of the conterminous United States. Map (scale 1:7,500,000). Annals of the Association of American Geographers, 77(1), 118-125.

Omernik, J.M., \& Griffith, G.E. (2014). Ecoregions of the conterminous United States: Evolution of a hierarchical spatial framework. Environmental Management, 54(6), 1249-1266.

Poverty Rates in Appalachia, 2010-2014. (2014). Retrieved from https://www.arc.gov/map/poverty-ratesin-appalachia-2010-

2014/\#: :text=Appalachian\%20poverty\%20rates\%20range\%20from,see\%20the\%20downloadabl e\%20Excel\%20file

Project: Patchwork Nation. (2008). Retrieved from https://www.jeffersoninst.org/projects/patchworknation

Scott Cato, M. (2013). The bioregional economy: Land, liberty and the pursuit of happiness. Routledge.

Sengupta, M., Xie, Y., Lopez, A., Habte, A., Maclaurin, G., \& Shelby, J. (2018). The National Solar Radiation Data Base (NSRDB). Renewable and Sustainable Energy Reviews, 89, 51-60.

Tonks, D.G. (2009). Validity and the design of market segments. Journal of Marketing Management, 25(3-4), 341-356.

Umesh, U.N. (1987). Transferability of preference models across segments and geographic areas. Journal of Marketing, 51, 59-70.

U.S. Bureau of Economic Analysis. (2019). Local Area Gross Domestic Product by County, 2001-2018. Retrieved from https://www.bea.gov/data/gdp/gdp-county-metro-and-other-areas

U.S. Census Bureau. (2018). American Community Survey. Retrieved from https://www.census.gov/programs-surveys/acs

U.S. Geological Survey. (2019). National Hydrography Dataset. Retrieved from https://www.usgs.gov/core-science-systems/ngp/national-hydrography/access-nationalhydrography-products

U.S. Geological Survey. (2020). The National Map: 3D Elevation Program. USGS Earth Resources Observation \& Science Center. Retrieved from https://basemap.nationalmap.gov/arcgis/rest/services/USGSTopo/MapServer

Woodard, C. (2012). American Nations: A History of the Eleven Rival Regional Cultures of North America. Penguin. 